\title{
Comparison of the Effects of Aerobic and Isokinetic Exercise Programs on Muscle Power, Cardiovascular Fitness, and Quality of Life in Multiple Sclerosis Patients: A Prospective, Randomized, Controlled Trial
}

\author{
(D) Sevgi Atar ${ }^{1}$, (D) Berrin Hüner², (D) Aliye Yıldırım Güzelant ${ }^{3}$, (D) Çiğdem Altun4, (D Dilek Ün Oğuzhanasiltürk5 ${ }^{5}$, (D) Sezgin Hacıoğlu6, \\ (D) Canan Berker6, (D) Mehmet Hayri Özgüzel6 \\ 1 University of Health Sciences Turkey, Prof. Dr. Cemil Taşcıoğlu City Hospital, Clinic of Physical Medicine and Rehabilitation, İstanbul, Turkey \\ 2University of Health Sciences Turkey, Gaziosmanpaşa Training and Research Hospital, Clinic of Physical Medicine and Rehabilitation, Istanbul, Turkey \\ 3 Private Reyap Hospital, Clinic of Physical Medicine and Rehabilitation, Tekirdağ, Turkey \\ 4 University of Health Sciences Turkey, Mehmet Akif Ersoy Training and Research Hospital, Clinic of Physical Medicine and Rehabilitation, Istanbul, Turkey \\ 5 University of Health Sciences Turkey, Kanuni Sultan Süleyman Training and Research Hospital, Clinic of Physical Medicine and Rehabilitation, istanbul, Turkey \\ 6Private Practice, Physical Medicine and Rehabilitation, İstanbul, Turkey
}

\section{Abstract}

Objective: This study aimed to evaluate the effects of aerobic and isokinetic rehabilitation exercise programs on muscle power, cardiovascular fitness, and quality of life (QoL) in multiple sclerosis (MS) patients.

Methods: A total of 40 MS patients who enrolled in a rehabilitation center were included. Twenty patients were randomly assigned to the aerobic exercise group (AEG), and 20 to the isokinetic exercise group (IEG). Patients in both groups participated in a rehabilitation program for 3 days per week for 8 weeks. In the AEG, walking treadmills were adjusted to the maximum speed at which a person could walk, and a 30-45-min run-walk exercise was performed. The patients in the IEG pedaled on a bicycle ergometer. The primary outcome measures were exercise capacity, muscle strength, cardiovascular fitness, and QoL.

Results: In IEG, post-treatment exertion values improved significantly for all parameters except maximum achievable heart rate ( $p<0.05)$. The post-treatment values for all QoL assessments also improved significantly compared to pre-treatment values in the AEG ( $p<0.05$ ). No significant differences in post-treatment values were observed between the two exercise groups $(p>0.05)$.

Conclusion: Exercise increases muscle strength, functionality, and QoL of MS patients if preventive measures and appropriate precautions, such as selecting exercises suitable for the functional condition of the patient are used.

Keywords: Aerobic, isokinetic, exercise, multiple sclerosis, quality of life

\section{INTRODUCTION}

Clinical signs can change during the course of multiple sclerosis (MS), causing muscle weakness and decreasing functional capacity, cardiac endurance, and quality of life (QoL) (1-3).
Muscle weakness affects many people with MS (4). Muscle weakness causes restrictions in daily life activities and decreases functions, such as walking, climbing up and down, sitting, and standing, and negatively affects participation in life and limits independence. This causes a further decrease in activity levels, 
particularly due to cardiopulmonary capacity, and a significant decrease in physiological condition $(5,6)$.

Until the end of the past century, MS patients were advised not to exercise because symptoms resulting from increased body temperature and nerve cell fatigue during exercise were thought to worsen any long-term benefit (7). However, current studies have reported that exercise should be encouraged due to its positive effects on muscle strength, endurance, and QoL (8-10).

Many studies have shown that physical activity increases cardiovascular capacity and muscle strength and that aerobic exercise (AE) and resistance training are beneficial. Additionally, MS patients can tolerate high-intensity interval exercise (11-15). Although there is no consensus on an exercise program, AE, or isokinetic exercise (IE), or different modifications can be used as therapy for MS patients. According to the needs of the patient, one or more of these exercises may be preferred to improve muscle strength, endurance, and functional capacity $(16,17)$.

While low-medium intensity AE in MS patients improves cardiopulmonary capacity and reduces fatigue, IE, which includes device-supported effective strengthening exercises that can be performed by applying force at different angular speeds and all degrees of motion, improve muscle strength, balance, and independent walking ability in MS patients (18-20).

The participation of MS patients in physical activities is a useful rehabilitation approach to manage symptoms without causing fatigue. It is important to encourage physical activity and strengthening exercises in MS patients $(21,22)$. No randomized prospective study has compared the results of AE and IE training in MS patients.

This study aimed to evaluate and compare the effectiveness of IE and AE on muscle strength, cardiovascular system, and QoL in MS patients.

\section{METHODS}

This study adhered to all relevant tenets of the Declaration of Helsinki and was approved by the Universitiy of Health Sciences Turkey, Okmeydani Training and Research Hospital Ethical Review Board (approval number: 128) and is registered at ClinicalTrials.gov (ref. NCT03805061). A minimum of 20 participants was needed for each group, with a $5 \%$ difference, and $80 \%$ power with a large effect size. Forty patients with MS aged 18-65 years who were being followed at the outpatient physical medicine and rehabilitation clinic were included in this study. Patients included in the study signed an "informed consent form".
Patients with a clinically definite diagnosis of MS according to the Poser criteria, disease duration of at least 1 year, and who could read and understand the MSQoL-54 questionnaire were enrolled. Patients who had a surgical operation on the knee joint in the last 3 months associated with an MS attack, a non-MS musculoskeletal disease (congenital anomaly or limb amputation), comorbid neurological (Parkinson's or Alzheimer's disease or polyneuropathy), and/or vestibular system disease, non-MS chronic systemic disease (diabetes mellitus, chronic obstructive pulmonary disease, hypertension, hyperlipidemia, serious cardiac disease, or malignancy), or other condition that would affect QoL, as well as those who were pregnant, were excluded from the study.

Descriptive information, such as age, gender, height, weight, occupation, marital status, and educational status, was recorded on a patient evaluation and follow-up form. Information about the disease, such as disease history, age at diagnosis, disease duration, type of disease, number of attacks, number of attacks per year, and symptoms that caused the patient to visit the health institution at the beginning of the disease, was collected individually. Motor, visual, and sensory symptoms; bladder and intestinal complaints; sexual problems; paroxysmal complaints; and cognitive or general dysfunction were assessed. Treatments used previously or currently and rehabilitation programs implemented up to the time of evaluation were also recorded.

The Expanded Disability Status scale (EDSS) score was determined by a trained and experienced specialist who had previously used the EDSS for treatment. These scores were employed as a measure of physical disability.

Each patient's QoL was assessed using the MSQoL-54 questionnaire. This scale is comprised of 54 questions and evaluates 12 areas: General health, energy and fatigue, role restriction due to physical problems, pain, physical-sexualsocial-cognitive functioning, health concerns, QoL, emotional well-being, and role restrictions due to emotional problems. Subjects were asked to complete the questionnaire on their own.

Muscle strength was assessed using a hand-held muscle test, and isokinetic muscle strength was measured using a numerical classification of the Medical Research Association with a Humac Norm isokinetic dynamometer (Computer Sports Medicine Inc., Stoughton, MA, USA). Isokinetic test data obtained during measurements at two angular velocities included the following:

- Quadriceps peak torque (PT) value [Newton meters (Nm)]

- Hamstring PT value (Nm)

- Hamstring/quadriceps $(\mathrm{H} / \mathrm{Q})$ ratio 
The PT-to-body mass index ratio (PT/BMI) was calculated by dividing the maximal torque values by the bodyweight of each patient. Muscle capacity reflects the muscle strength produced by the musculoskeletal system and is often measured in peak force.

Cardiopulmonary capacity indicates the body's capacity to endure long-term exercise and is usually measured by peak oxygen consumption $\left(\mathrm{VO}_{2}\right.$ max) $(9,23,24)$.

Exercise capacity was assessed using the NoravTrackmaster TMX 425 treadmill exercise device using the modified Bruce protocol. Indirect maximum $\mathrm{VO}_{2}$ (iVO 2 max) and metabolic equivalent values were calculated using the heart rate obtained during submaximal treadmill exercise. The target heart rate, calculated as (220-age) $\times(0.70)$, was used to calculate $70-80 \%$ of each patient's maximum heart rate. For those exhibiting low sensitivity to exercise and low heat resistance, this figure was multiplied by $65 \%$.

Functional capacity was measured by asking patients to walk at a comfortable pace as quickly as possible for 6 min in the hospital hallway along a 20-m ASTA flat track. The distance traveled in 6 min. was recorded in meters.

All participants were randomly assigned to two groups using a computer-generated block randomization list that was initiated by an independent individual not involved in patient treatment.

Of the 40 participants, 20 were randomly assigned to the $\mathrm{AE}$ group (AEG), and 20 to the IE group (IEG). Patients in both groups participated in a rehabilitation program for 3 days per week for 8 weeks. In the AEG, we carried out the AE daily protocol reported by Petajan et al. (25). According to that protocol, each training session was comprised of a warm-up at $30 \%$ of maximum $\mathrm{iVO}_{2}$ max for $5 \mathrm{~min}$, followed by $60 \%$ of $\mathrm{iVO}_{2}$ max for $30 \mathrm{~min}$ and a 5-min cool down period. The walking treadmills were adjusted to the maximum speed at which a person could walk, and a 30-45-min run-walk exercise was performed according to the progressive training method. The patients in the IEG pedaled on a bicycle ergometer for $5 \mathrm{~min}$ at low resistance as a warm-up exercise before starting the exercise, and 5-10 min of stretching exercises were performed to cool down after the exercise. The IE program was comprised of 10 repetitions at $60^{\circ} / \mathrm{sec}, 90^{\circ} / \mathrm{sec}$, $120 \%$ sec, and 10 at $180 \% / \mathrm{sec}$, with a 30 -sec rest period between sets. All patients in both groups were assessed before and after treatment.

All participants were analyzed and evaluated at the beginning and the end of the study. The data obtained were recorded, and the study was terminated.

\section{Statistical Analysis}

Analyses were performed using SPSS 15.0 for Windows (SPSS Inc., Chicago, IL, USA.) To compare the two groups, Student's t-test was used for normally distributed independent numerical variables, and the Mann-Whitney U-test was used for non-normally distributed independent numerical variables. Between-group comparisons of categorical variables were made using the chisquare or Fisher's tests. Pearson's and Spearman's correlation analyses were used to determine if any of the factors significantly affected the outcomes. Using the independent sample t-test and Cohen's d-value that a large effect on the physical health in MS $(d=0.87)$ with a total sample size of 40 participants, power was estimated at $84 \%$ at a significance level of $\alpha=0.05$ (26). In addition, a regression model was created for the MSQoL-54 using variables that were significant. P values $<0.05$ were considered significant.

\section{RESULTS}

Of the 60 MS patients admitted to our outpatient clinic, 20 were excluded from the study because of respiratory system problems (3 cases), branch block (2 cases), issues with the resting electrocardiogram (1 case), and a delay in intraventricular conduction (1 case); 1 each had intracranial sinus thrombosis, polio sequelae, pregnancy, and breast cancer; 2 had a congenital hip dislocation, and 5 reported a history of MS attack in the last 3 months; 2 patients refused to participate in the study. Of the 40 MS patients included in the study, 13 (32.5\%) were male, and 27 (67.5\%) were female (Figure 1).

Of the 20 patients in the AEG, 14 were female and 6 were male, and their mean age was $39.2 \pm 6.0$ years. Of the 20 patients in the IEG, 13 were female and 7 were male, and their mean age was $37.7 \pm 9.7$ years. No significant differences were observed in the mean age or sex ratio of the study groups ( $p=0.561$, $p=0.736$ ). The mean height of the patients in the AEG was $165.3 \pm 9.4 \mathrm{~cm}$, mean weight was $73.4 \pm 12.9 \mathrm{~kg}$, and mean BMI was $26.9 \pm 3.4 \mathrm{~kg} / \mathrm{m}^{2}$. The mean height of the patients in the IEG was $162.4 \pm 10.1 \mathrm{~cm}$, weight was $67.5 \pm 10.8 \mathrm{~kg}$, and BMI was $26 \pm 3.8 \mathrm{~kg} / \mathrm{m}^{2}$. No significant differences were observed between the groups in mean height, weight, or BMI ( $p=0.361, p=0.125, p=0.411)$. Twenty $(50 \%)$ of the cases were smokers. Twenty-five patients (62.5\%) were receiving immunomodulatory treatment. Two patients had undergone an MS rehabilitation program since the diagnosis. The disease duration of the patients in the AEG was $6.9 \pm 4.4$ years, and the mean EDSS was 1.6 \pm 1.3 . The disease duration in the IEG was $5.8 \pm 4.4$ years, and the mean EDSS was $1.7 \pm 1.5$. No significant differences were observed between the groups $(p=0.334$, 
$p=0.912$ ). MS was diagnosed in 5 first-degree relatives and 2 second-degree relatives. The age at MS diagnosis was $32.3 \pm 8.7$ years in the AEG and $31.9 \pm 9.6$ years in the IEG $(p=0.652)$. The mean number of attacks in the last 2 years was $1.8 \pm 0.9$ in the AEG and $1.6 \pm 1.03$ in the IEG $(p=0.512)$.

Ten patients were civil servants (25\%), 13 were housewives (32.5\%), 8 were sitting workers (20\%), 5 were standing workers (12.5\%), and 4 were tradesmen (10\%).
When education levels were examined, 18 (45\%) were primary school graduates, 5 (12.5\%) were secondary school graduates, 11 (27.5\%) were high school graduates, and 6 (15\%) had higher education. No significant differences were observed between the groups in pre-treatment effort, muscle strength, or the MSQoL-54 assessments (Table 1).

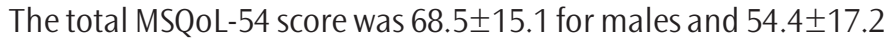
for females. The MSQoL-54 physical sub-scale scores were 69 \pm 13.5

Table 1. The values of the assessment of the pre-treatment muscle strength and quality of life in study groups

\begin{tabular}{|l|l|l|l|}
\hline & AE $( \pm$ SD) & IE $( \pm$ SD) & p \\
\hline $\mathbf{6 0} /$ sec PT (extensor) & $88.7 \pm 33$ & $93.6 \pm 40.9$ & 0.679 \\
\hline $\mathbf{6 0} /$ sec PT (flexor) & $45.5 \pm 22.9$ & $47 \pm 24.2$ & 0.841 \\
\hline $\mathbf{6 0} /$ sec H/Q & $0.5 \pm 0.1$ & $0.5 \pm 0.1$ & 0.590 \\
\hline $\mathbf{6 0} /$ sec PT/BMI & $111.5 \pm 49.3$ & $136.1 \pm 65.5$ & 0.188 \\
\hline $\mathbf{1 8 0} /$ sec PT (extensor) & $42.3 \pm 17.5$ & $45.3 \pm 26.7$ & 0.672 \\
\hline $\mathbf{1 8 0} /$ sec PT (flexor) & $20.8 \pm 11.6$ & $22.3 \pm 18.9$ & 0.665 \\
\hline $\mathbf{1 8 0} /$ sec H/Q & $0.5 \pm 0.2$ & $0.5 \pm 0.2$ & 0.885 \\
\hline MSQ0L-54 (total) & $56 \pm 19.2$ & $61.8 \pm 16.1$ & 0.326 \\
\hline MSQ0L-54 (physical) & $58.3 \pm 19.2$ & $62.3 \pm 14.3$ & 0.463 \\
\hline MSQ0L-54 (cognitive) & $60.9 \pm 18.2$ & 0.318 \\
\hline
\end{tabular}

AE: Aerobic exercise, IE: Isokinetic exercise, H/Q: Hamstring/quadriceps ratio, BMI: Peak torque-to-body mass index ratio, MSQOL-54: Multiple Sclerosis Quality of Life-54 questionnaire, PT: Peak torque, SD: Standard deviation

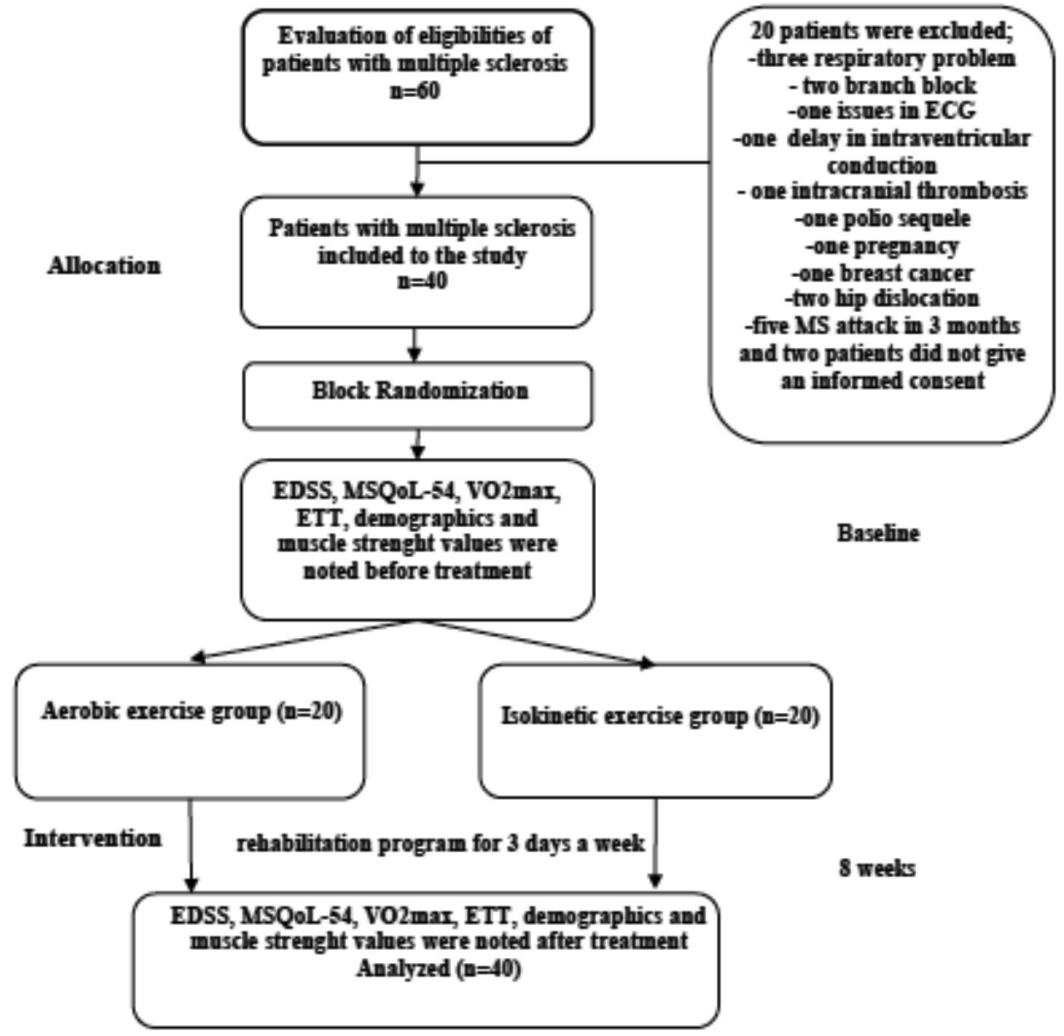

Figure 1. The flowchart diagram of this study

ETT: Exercise tolerance test, MSQOL-54: Multiple Sclerosis Quality of Life-54 questionnaire, EDSS: The Expanded Disability Status scale 
for males and $56.4 \pm 17$ for females. The MSQoL-54 cognitive sub-scale scores were $67.4 \pm 16.9$ for males and $52.9 \pm 21.7$ for females. Significant differences were observed between genders before treatment ( $p=0.021 ; p=0.030 ; p=0.048$, respectively). No significant difference in the MSQoL-54 total scores was observed according to educational status $(p=0.349)$. Furthermore, the total, physical, and cognitive QoL scores did not differ according to occupational status ( $p=0.083 ; p=0.427 ; p=0.150$, respectively). The MSQoL-54 score was negatively correlated with the EDSS score and positively correlated with $\mathrm{VO}_{2} \max$, exercise tolerance test (ETT) time, 6-min walking distance, and $60 \% \mathrm{sec}$ and $180^{\circ} / \mathrm{sec}$ PT/BMI scores before treatment (Table 2).

In the AEG, the differences between pre-treatment and posttreatment exercise test scores were significant for all evaluations, except $60^{\circ} / \mathrm{sec}$ flexor PT, $60^{\circ} / \mathrm{sec} \mathrm{H} / \mathrm{Q}$, and $180^{\circ} / \mathrm{sec} \mathrm{H} / \mathrm{Q}$. Posttreatment evaluations revealed significant improvements in all other measures. The post-treatment values for all QoL assessments also improved significantly compared to the pretreatment values in the AEG (Table 3).

In the IEG, post-treatment exertion values improved significantly for all parameters, except maximum achievable heart rate. Significant changes were detected in all muscle strength measures, except $60^{\circ} / \mathrm{sec}$ flexor PT, $60^{\circ} / \mathrm{sec} \mathrm{H} / \mathrm{Q}$, and $180^{\circ} /$ sec $\mathrm{H} / \mathrm{Q}$. Significant improvements were observed in all other evaluations, including the QoL assessments, compared to pretreatment values (Table 4). No significant differences were observed between the groups after treatment for measures of stress, muscle strength, or the MSQoL-54 (Table 5).

The two groups did not differ significantly in terms of changes between pre- and post-tests of stress, muscle strength, or the MSQoL-54 (Table 6).

\section{DISCUSSION}

Petajan et al. (25) carried out an exercise program (EP) for MS patients and described the duration and goals of this program in detail. According to this EP, moderate-intensity aerobic activity for an average of 30 min twice per week and strengthening exercises involving major muscle groups twice per week were recommended for individuals with MS. We carried out a lower extremity strengthening program in the AEG for 30 min 3 times per week, and repeatedly in the IEG 3 times per week at determined angles. None of the patients in either group dropped out of their EPs due to fatigue or any other reason. All patients continued to perform their exercises on the specified days and completed the EP.

An IE study conducted by Lambert et al. (27) employed two MS groups and a control. Using a Cybex Norm dynamometer, the

\begin{tabular}{|c|c|c|c|c|}
\hline & & MSQoL 54 (total) & MSQoL-54 (physical) & MSQoL-54 (cognitive) \\
\hline \multirow{2}{*}{ Age } & $r$ & -0.056 & -0.171 & 0.031 \\
\hline & $p$ & 0.742 & 0.298 & 0.850 \\
\hline \multirow{2}{*}{ Disease duration (years) } & $r$ & -0.097 & -0.055 & -0.059 \\
\hline & $p$ & 0.569 & 0.740 & 0.723 \\
\hline \multirow{2}{*}{ Last 2 years attack issue } & $r$ & -0.218 & -0.356 & -0.128 \\
\hline & $p$ & 0.201 & 0.028 & 0.444 \\
\hline \multirow{2}{*}{ EDSS } & $r$ & -0.547 & -0.553 & -0.471 \\
\hline & $p$ & $<0.001$ & $<0.001$ & 0.002 \\
\hline \multirow{2}{*}{$\mathrm{VO}_{2}$ maximum } & $r$ & 0.453 & 0.228 & 0.524 \\
\hline & $p$ & 0.005 & 0.164 & 0.001 \\
\hline \multirow{2}{*}{ ETT duration (sec) } & $r$ & 0.445 & 0.327 & 0.433 \\
\hline & $p$ & 0.006 & 0.042 & 0.006 \\
\hline \multirow{2}{*}{6 min walking distance } & $r$ & 0.461 & 0.375 & 0.430 \\
\hline & $p$ & 0.004 & 0.019 & 0.006 \\
\hline \multirow{2}{*}{$60^{\circ} / \mathrm{sec} \mathrm{PT} / \mathrm{BMI}$} & $r$ & 0.594 & 0.517 & 0.475 \\
\hline & $p$ & $<0.001$ & 0.001 & 0.002 \\
\hline \multirow{2}{*}{$180^{\circ} / \mathrm{sec} \mathrm{PT} / \mathrm{BMI}$} & $r$ & 0.434 & 0.348 & 0.403 \\
\hline & $p$ & 0.007 & 0.030 & 0.011 \\
\hline
\end{tabular}


Table 3. The pretreatment and posttreatment values of the stress-test evaluations, muscle strength assessments, and quality of life in the aerobic exercise group

\begin{tabular}{|c|c|c|c|}
\hline & Before treatment $( \pm \mathrm{SD})$ & After treatment $( \pm \mathrm{SD})$ & $\mathrm{p}$ \\
\hline TA systolic & $126 \pm 17$ & $121.5 \pm 15.4$ & $<0.001$ \\
\hline TA diastolic & $75.5 \pm 7.7$ & $72.9 \pm 7.2$ & $<0.001$ \\
\hline Resting heart rate & $86.3 \pm 9.5$ & $83 \pm 9.3$ & $<0.001$ \\
\hline Maximum heart rate & $146.5 \pm 16.1$ & $141.8 \pm 17.5$ & 0.003 \\
\hline $\mathrm{VO}_{2}$ maximum & $24.8 \pm 11.1$ & $30.7 \pm 10.1$ & 0.004 \\
\hline MET & $8.1 \pm 4.3$ & $8.9 \pm 2.9$ & 0.039 \\
\hline ETT duration (sec) & $606 \pm 208.5$ & $751.7 \pm 176$ & 0.001 \\
\hline $60^{\circ} / \mathrm{sec}$ PT (extensor) & $88.7 \pm 33$ & $96.4 \pm 38.3$ & 0.009 \\
\hline $60 \%$ sec PT (flexor) & $45.5 \pm 22.9$ & $50.2 \pm 22.7$ & 0.071 \\
\hline $60 \% / \mathrm{sec} \mathrm{H} / \mathrm{Q}$ & $0.5 \pm 0.1$ & $0.5 \pm 0.1$ & 0.210 \\
\hline $60 \%$ sec PT/BMI & $111.5 \pm 49.3$ & $121.6 \pm 51$ & 0.025 \\
\hline $180^{\circ} /$ sec PT (extensor) & $42.3 \pm 17.5$ & $53.3 \pm 20.2$ & $<0.001$ \\
\hline $180^{\circ} / \mathrm{sec}$ PT (flexor) & $20.8 \pm 11.6$ & $26 \pm 12.9$ & 0.036 \\
\hline $180^{\circ} / \mathrm{sec} \mathrm{H} / \mathrm{Q}$ & $0.5 \pm 0.2$ & $0.5 \pm 0.2$ & 0.915 \\
\hline 6 minutes walking distance & $459 \pm 90.8$ & $491.5 \pm 79.9$ & $<0.001$ \\
\hline MSQ0L-54 (total) & $56 \pm 19.2$ & $58.5 \pm 19.5$ & $<0.001$ \\
\hline MSQ0L-54 (physical) & $58.3 \pm 19.2$ & $61.3 \pm 18.7$ & $<0.001$ \\
\hline MSQ0L-54 (cognitive) & $54 \pm 23.7$ & $56.2 \pm 24$ & $<0.001$ \\
\hline
\end{tabular}

Table 4. The pretreatment and posttreatment values of the exercise tests, muscle strengths, quality of life in the isokinetic exercise group

\begin{tabular}{|c|c|c|c|}
\hline & Before treatment $( \pm \mathrm{SD})$ & After treatment $( \pm S D)$ & $\mathrm{p}$ \\
\hline TA systolic & $123.9 \pm 15.5$ & $120.1 \pm 15.8$ & $<0.001$ \\
\hline TA diastolic & $75.6 \pm 6.7$ & $73.1 \pm 7.1$ & 0.001 \\
\hline Resting heart rate & $86.2 \pm 9.3$ & $82.9 \pm 10.4$ & 0.001 \\
\hline Maximum heart rate & $141.4 \pm 19.4$ & $140.4 \pm 19.1$ & 0.609 \\
\hline $\mathrm{VO}_{2}$ maximum & $25.4 \pm 9.7$ & $29.4 \pm 11.6$ & 0.007 \\
\hline MET & $7.3 \pm 2.9$ & $8.7 \pm 3.3$ & $<0.001$ \\
\hline ETT duration (sec) & $595.8 \pm 209.9$ & $698.4 \pm 292.7$ & 0.002 \\
\hline $60^{\circ} / \mathrm{sec}$ PT (extensor) & $93.6 \pm 40.9$ & $103.3 \pm 41.2$ & 0.032 \\
\hline $60^{\circ} / \mathrm{sec}$ PT (flexor) & $47 \pm 24.2$ & $52.9 \pm 25.1$ & 0.065 \\
\hline $60^{\circ} / \mathrm{sec} \mathrm{H} / \mathrm{Q}$ & $0.5 \pm 0.1$ & $0.5 \pm 0.1$ & 0.855 \\
\hline $60^{\circ} / \mathrm{sec} \mathrm{PT} / \mathrm{BMI}$ & $136.1 \pm 65.5$ & $152.1 \pm 65.4$ & 0.006 \\
\hline $180^{\circ} / \mathrm{sec}$ PT (extensor) & $45.3 \pm 26.7$ & $55.9 \pm 27.6$ & $<0.001$ \\
\hline $180^{\circ} / \mathrm{sec}$ PT (flexor) & $22.3 \pm 18.9$ & $30.7 \pm 22.1$ & 0.002 \\
\hline $180^{\circ} / \mathrm{sec} \mathrm{H} / \mathrm{Q}$ & $0.5 \pm 0.2$ & $0.5 \pm 0.2$ & 0.672 \\
\hline 6 minutes walking distance & $461.4 \pm 95.8$ & $496.3 \pm 101.6$ & $<0.001$ \\
\hline MSQ0L-54 (total) & $61.8 \pm 16.1$ & $63.8 \pm 16.4$ & 0.001 \\
\hline MSQ0L-54 (physical) & $62.3 \pm 14.3$ & $64.4 \pm 14.7$ & $<0.001$ \\
\hline MSQ0L-54 (cognitive) & $60.9 \pm 18.2$ & $63.1 \pm 18.7$ & 0.001 \\
\hline
\end{tabular}




\begin{tabular}{|c|c|c|c|}
\hline & Aerobic exercise $( \pm S D)$ & Isokinetic exercise $( \pm$ SD) & $p$ \\
\hline TA systolic & $121.5 \pm 15.4$ & $120.1 \pm 15.8$ & 0.735 \\
\hline TA diastolic & $72.9 \pm 7.2$ & $73.1 \pm 7.1$ & 0.947 \\
\hline Resting heart rate & $83 \pm 9.3$ & $82.9 \pm 10.4$ & 0.975 \\
\hline Maximum heart rate & $141.8 \pm 17.5$ & $140.4 \pm 19.1$ & 0.803 \\
\hline $\mathrm{VO}_{2}$ maximum & $30.7 \pm 10.1$ & $29.4 \pm 11.6$ & 0.600 \\
\hline MET & $8.9 \pm 2.9$ & $8.7 \pm 3.3$ & 0.820 \\
\hline ETT duration (sec) & $751.7 \pm 176$ & $698.4 \pm 292.7$ & 0.808 \\
\hline $60^{\circ} / \mathrm{sec}$ PT (extensor) & $96.4 \pm 38.3$ & $103.3 \pm 41.2$ & 0.586 \\
\hline $60^{\circ} / \mathrm{sec}$ PT (flexor) & $50.2 \pm 22.7$ & $52.9 \pm 25.1$ & 0.728 \\
\hline $60^{\circ} / \mathrm{sec} \mathrm{H} / \mathrm{Q}$ & $0.5 \pm 0.1$ & $0.5 \pm 0.1$ & 0.659 \\
\hline $60 \%$ sec PT/BMI & $121.6 \pm 51$ & $152.1 \pm 65.4$ & 0.109 \\
\hline 180\%/sec PT (extensor) & $53.3 \pm 20.2$ & $55.9 \pm 27.6$ & 0.741 \\
\hline 180\%/sec PT (flexor) & $26 \pm 12.9$ & $30.7 \pm 22.1$ & 0.414 \\
\hline $180^{\circ} / \mathrm{sec} \mathrm{H} / \mathrm{Q}$ & $0.5 \pm 0.2$ & $0.5 \pm 0.2$ & 0.767 \\
\hline MSQ0L-54 (total) & $58.5 \pm 19.5$ & $63.8 \pm 16.4$ & 0.379 \\
\hline MSQ0L-54 (physical) & $61.3 \pm 18.7$ & $64.4 \pm 14.7$ & 0.572 \\
\hline MSQ0L-54 (cognitive) & $56.2 \pm 24$ & $63.1 \pm 18.7$ & 0.324 \\
\hline
\end{tabular}

Table 6. Differences in change of the post-treatment values of stress tests, muscle strength assessments, quality of life assessments in aerobic and isokinetic exercise groups compared to pre-treatment values

\begin{tabular}{|c|c|c|c|c|}
\hline & $\begin{array}{l}\text { Aerobic exercise change } \\
( \pm \text { SD) }\end{array}$ & $\begin{array}{l}\text { Isokinetic exercise change } \\
( \pm \text { SD) }\end{array}$ & Change difference & $p$ \\
\hline TA systolic & $4.5 \pm 2.7$ & $3.9 \pm 1.7$ & 0.600 & 0.407 \\
\hline TA diastolic & $2.6 \pm 1.8$ & $2.5 \pm 2$ & 0.100 & 0.601 \\
\hline Resting heart rate & $3.4 \pm 2.9$ & $3.3 \pm 3.7$ & 0.050 & 0.419 \\
\hline Maximum heart rate & $4.7 \pm 6$ & $1.0 \pm 8.6$ & 3.650 & 0.177 \\
\hline $\mathrm{VO}_{2}$ maximum & $5.9 \pm 8.1$ & $4.0 \pm 8.8$ & 1.871 & 0.746 \\
\hline MET & $0.8 \pm 3.6$ & $1.6 \pm 1.8$ & 0.772 & 0.652 \\
\hline ETT duration (sec) & $145.7 \pm 174$ & $102.6 \pm 263.2$ & 43.050 & 0.839 \\
\hline $60^{\circ} / \mathrm{sec}$ PT (extensor) & $12.2 \pm 7.7$ & $18.9 \pm 9.7$ & 2.000 & 0.065 \\
\hline $60^{\circ} / \mathrm{sec}$ PT (flexor) & $11.1 \pm 4.8$ & $13.4 \pm 5.9$ & 1.150 & 0.768 \\
\hline $60^{\circ} / \mathrm{sec} \mathrm{H} / \mathrm{Q}$ & $0.0 \pm 0.1$ & $0.0 \pm 0.1$ & 0.026 & 0.899 \\
\hline $60 \%$ sec PT/BMI & $10.2 \pm 18.7$ & $16 \pm 23.4$ & 5.850 & 0.405 \\
\hline $180^{\circ} /$ sec PT (extensor) & $11.1 \pm 7.6$ & $10.6 \pm 8.9$ & 0.500 & 0.478 \\
\hline $180^{\circ} / \mathrm{sec}$ PT (flexor) & $10.4 \pm 5.2$ & $8.4 \pm 13$ & 3.250 & 0.795 \\
\hline $180^{\circ} / \mathrm{sec} \mathrm{H} / \mathrm{Q}$ & $0.0 \pm 0.2$ & $0.0 \pm 0.2$ & 0.027 & 0.988 \\
\hline MSQ0L-54 (total) & $2.5 \pm 1.7$ & $2.0 \pm 1.8$ & 0.528 & 0.791 \\
\hline MSQ0L-54 (physical) & $3.0 \pm 2.7$ & $2.1 \pm 1.3$ & 0.943 & 0.465 \\
\hline MSQ0L-54 (cognitive) & $2.2 \pm 1.7$ & $2.2 \pm 2.3$ & 0.049 & 0.508 \\
\hline
\end{tabular}


researchers tested five repetitions of knee extensor and flexor exercises at $30^{\circ} / \mathrm{sec}, 60 \% \mathrm{sec}, 90 \% \mathrm{sec}, 120^{\circ} / \mathrm{sec}$, and $180^{\circ} / \mathrm{sec}$ angular speeds, two at submaximal and three at maximal effort. They measured the PT values after applying the IE program. Extensor and flexor values at all speeds were divided into those for the dominant and the non-dominant lower limbs. The results revealed no significant difference in power generation between the dominant and non-dominant extremities in either group. However, significant differences in non-dominant limb extension and dominant and non-dominant flexion values were found in both groups. We used the extensor and flexor muscles of both lower extremities at the commonly preferred angular velocities of $60^{\circ} / \mathrm{sec}$ and $180^{\circ} / \mathrm{sec}$ for the muscle strength measurement but did not apply the dominant-non-dominant distinction.

In a study by Gehlsen et al. (28), 10 MS patients with EDSS scores $<6$ underwent an aquatic EP for 10 weeks. They then used a Cybex II isokinetic dynamometer at $60 \% \mathrm{sec}, 120^{\circ} / \mathrm{sec}$, and $180^{\circ} /$ sec to assess muscle strength. They measured the PT values of the knee joint flexor and extensor muscles at $240 \%$ sec and $300 \%$ sec and found a significant increase in the PT values of the knee extensor muscles. In contrast, in our study, a significant increase in $60^{\circ} / \mathrm{sec}$ and $180 \%$ sec PT extensor and $180^{\circ} / \mathrm{sec}$ PT flexor muscle strength was detected in both exercise groups before and after the treatment (Table 5, 6). In agreement with our results, Hameau et al. (7) found an increase in knee extensor muscle strength after their rehabilitation program.

Romberg et al. (8) evaluated QoL, gait, and muscle strength after a 23-week AE program performed at home with $91 \mathrm{MS}$ patients whose initial EDSS scores were 1.0-5.5. They reported a significant increase in those parameters but detected no change in $\mathrm{VO}_{2}$ max values. In our study, mean $\mathrm{VO}_{2}$ max before and after treatment improved significantly in both groups (Table 5, 6). In a 4-week study of a bicycle ergometer EP, Mostert and Kesselring (9) reported that the aerobic capacity of the exercise group increased significantly ( $\mathrm{VO}_{2} \max ,+13 \%$; working capacity, $\left.+11 \%\right)$, in agreement with our results. We found a significant increase in the mean 6-min walking distance at the end of treatment (Table $5,6)$.

In our study, the MSQoL-54 values were positively correlated with $\mathrm{VO}_{2}$ max, the EDSS score, ETT duration, 6-min walking distance, and the $60^{\circ} / \mathrm{sec}$ and $180^{\circ} / \mathrm{sec} \mathrm{PT} / \mathrm{BMI}$ (Table 3). Similarly, the study by Petajan et al. (25), investigated the effects of exercise on QoL in MS patients. Patients with a mean EDSS score of $3.8 \pm 0.3$ exhibited significant improvements in $\mathrm{VO}_{2}$ max values, from a mean of $24.2 \pm 0.2$ to $29.4 \pm 1.3$, as a result of a 15-week EP. They also reported significant improvements in QoL.
In another study, 49 patients with a mean EDSS score of 5.1 \pm 1.4 , who were diagnosed with MS according to the Poser criteria, exercised 1 day per week for 6 weeks. The Barthel Index (BI) and Fatigue Severity Scale scores were evaluated before and after the study, and the Borg Scale scores were evaluated based on manual muscle strength, $10-\mathrm{m}$ and $20-\mathrm{m}$ walking times, and MSQoL-54 results. The results showed a 3.6\% increase in the BI in the exercise group. A significant increase in muscle strength $(+4.3 \%)$ was observed in the exercise group, as well as significant decreases in the 10-m and 20-m walking times. A 9.8\% increase in the physical health score and a $7.7 \%$ increase in the physical functioning score were detected on the MSQoL-54 sub-scores (11). We also found significant increases in the 6-min walking distance, muscle strength, and MSQoL-54 scores in both exercise groups (Table 3, 4).

Fatigue associated with low QoL is one of the most important reasons restricting people's participation in daily life activities by reducing their work performance. Somatic symptoms in MS are also at the forefront (29-31). Fatigue in MS and increases in body temperature or ambient temperature increase the sensitivity of demyelinated myelin sheaths, slows down nerve conduction, and worsen symptoms (32). This can be a limiting factor for physical activity. Exercise should be done by reducing heat production to prevent exacerbating the symptoms. Submaximal exercise is ideal for MS patients, as it does not increase fatigue or body temperature. While the cardiopulmonary exertion rate is $70-80 \%$ in the healthy population, a value of $65 \%$ of the $\mathrm{VO}_{2}$ max is recommended for MS patients when aerobic exercises are performed 3 or more times per week $(23,24)$. In our study, exercise was performed at $60 \%$ of $\mathrm{iVO}_{2}$ max without increasing body temperature.

Muscle weakness in the upper limbs alone is uncommon, as weakness usually occurs in the lower limbs $(5,6,33)$. We also detected no muscle weakness in the upper extremities. Muscle strength was evaluated using a manual muscle test and classified according to the EDSS score. Exercises intended to increase muscle strength and function should be done daily. Prolonged strengthening exercises are thought to cause fatigue and decrease functional capacity in MS patients. Although exercises to increase muscle strength are generally reported to offer minimal benefits, recent studies have reported positive results (34-36). Nevertheless, patients should be warned about intense activity, and the need for frequent breaks during exercise should be emphasized (37).

Despite that many studies have shown the benefits of exercise in MS patients, this patient population is less active due to 
movement disorders, difficulties with tasks that they have accomplished before, or fatigue and balance problems. Exercise is a useful rehabilitation strategy for MS patients to regain function, optimize QoL, and increase participation in daily life activities. Although there are individual differences at each level of disability, patients should be supported and encouraged to exercise.

\section{Study Limitations}

Several limitations of our study should be mentioned. Our inclusion and exclusion criteria were standard factors and valid in all studies. The limitations of this study included the lack of a long follow-up period and no double-blindness.

\section{CONCLUSION}

We examined the contribution of exercise to muscle strength, functional capacity, and QoL in MS patients and compared two exercise approaches. The results will contribute to the existing literature in this area. Exercise has not been recommended for MS patients because it was thought to increase body temperature and fatigue level. Our results indicate that exercise increases muscle strength, functionality, and QoL if preventive measures and appropriate precautions are taken, such as selecting exercises suitable for the functional condition of the patient, including AE, such as cycling and walking, and IE that does not result in fatigue.

\section{Ethics}

Ethics Committee Approval: This study adhered to all relevant tenets of the Declaration of Helsinki and was approved by the Universitiy of Health Sciences Turkey, Okmeydani Training and Research Hospital Ethical Review Board (approval number: 128) and is registered at ClinicalTrials.gov (ref. NCT03805061).

Informed Consent: Patients included in the study signed an "informed consent form".

Peer-review: Externally peer-reviewed.

\section{Authorship Contributions}

Surgical and Medical Practices: S.A., Concept: S.A., B.H., Design: S.A., C.B., M.H.Ö., Data Collection or Processing: S.A., B.H., A.Y.G., Analysis or Interpretation: S.A., C..A., D.Ü.O., Literature Search: S.A., S.H., Writing: S.A.

Conflict of Interest: No conflict of interest was declared by the authors.

Financial Disclosure: The authors declared that this study received no financial support.

\section{REFERENCES}

1. Tunalı G. Diagnostic criteria in multiple sclerosis. Special issue of multiple sclerosis. Turkey J Clinical Neuer 2004;2:161-209.

2. Hemmer B, Cepok S, Nessler S, Sommer N. Pathogenesis of multiple sclerosis: an update on immunology. Curr Opin Neurol 2002;15:22731.

3. Ozgul A, Alaca R. Rehabilitation in multiple sclerosis. Ozcan 0, Arpacioglu 0, Turan B (Editors). Neurorehabilitation. Bursa: Gunes and Nobel Medicine Bookstore; 2000. p.183-205.

4. Turhan N, Bayramoglu M. Multiple sclerosis. Oguz H, Dursun E, Dursun $\mathrm{N}$ (Editors). Medical rehabilitation. Istanbul: Nobel Medicine Bookstore; 2004. p.649-63.

5. Thompson AJ. Neurorehabilitation in multiple sclerosis: foundations, facts and fiction. Curr Opin Neurol 2005;18:267-71.

6. Ropper AH, BrownRH. Multiple sclerosis and allied de myelinative diseases. Adams and Victor's principles of neurology. 8th ed. New York: McGraw Hill Co; 2005. p.771-96.

7. Hameau S, Bensmail D, Roche N, Zory R. Adaptations of fatigue and fatigability after a short intensive, combined rehabilitation program in patients with multiple sclerosis. J Rehabil Med 2018;50:59-66.

8. Romberg A, Virtanen A, Ruutiainen J, Aunola S, Karppi SL, Vaara M, et al. Effects of a 6-month exercise program on patients with multiple sclerosis: a randomized study. Neurology 2004;63:2034-8.

9. Mostert S, Kesselring J. Effects of a short-term exercise training program on aerobic fitness, fatigue, health perception and activity level of subjects with multiple sclerosis. Mult Scler 2002;8:161-8.

10. Idiman E, Uzunel F, Ozakbas S, Yozbatiran N, Oguz M, Callioglu B, et al Cross-cultural adaptation and validation of multiple sclerosis quality of life questionnaire (MSQOL-54) in a Turkish multiple sclerosis sample. J Neurol Sci 2006;240:77-80

11. Mutluay FK, Tekeoglu A, Saip S, Altintas A, Siva A. Group exercise training approach to multiple sclerosis rehabilitation. Nobel Med 2008;4:20-6.

12. Taylor RS. Rehabilitation of persons with multiple sclerosis; physical medicine and rehabilitation (Braddom RL, ed). 2nd edition, Philadelphia: WB Saunders Company Publication; 2000. p.1177-90.

13. Schwid SR, Thornton CA, Pandya S, Manzur KL, Sanjak M, Petrie MD, et al. Quantitative assessment of motor fatigue and strength in MS. Neurology 1999;53:743-50.

14. Ponichtera-Mulcare JA. Exercise and multiple sclerosis. Med Sci Sports Exerc 1993;25:451-65.

15. Freeman JA. Improving mobility and functional independence in persons with multiple sclerosis. J Neurol 2001;248:255-9.

16. Smith M, Neibling B, Williams G, Birks M, Barker R. A qualitative study of active participation in sport and exercise for individuals with multiple sclerosis. Physiother Res Int 2019;24:e1776.

17. Halabchi F, Alizadeh Z, Sahraian MA, Abolhasani M. Exercise prescription for patients with multiple sclerosis; potential benefits and practical recommendations. BMC Neurol 2017;17:185.

18. Kara B, Küçük F, Poyraz EC, Tomruk MS, İdıman E. Different types of exercise in Multiple Sclerosis: Aerobic exercise or Pilates, a single-blind clinical study. J Back Musculoskelet Rehabil 2017;30:565-73.

19. Reynolds ER, Ashbaugh AD, Hockenberry BJ, McGrew CA. Multiple Sclerosis and Exercise: A Literature Review. Curr Sports Med Rep 2018;17:31-5. 
20. Ramari C, Hvid LG, David AC, Dalgas U. The importance of lowerextremity muscle strength for lower-limb functional capacity in multiple sclerosis: systematic review. Ann Phys Rehabil Med 2020;63:123-37.

21. Abonie US, Hoekstra F, Seves BL, Woude LHVV, Dekker R, Hettinga FJ. Associations between activity pacing, fatigue, and physical activity in adults with multiple sclerosis: a cross sectional study. J Funct Morphol Kinesiol 2020;5:43

22. White LJ, Dressendorfer RH. Exercise and multiple sclerosis. Sports Med 2004;34:1077-100.

23. Dalgas U, Stenager E, Ingemann-Hansen T. Multiple sclerosis and physical exercise: recommendations for the application of resistanceendurance- and combined training. Mult Scler 2008;14:35-53.

24. Gries KJ, Raue U, Perkins RK, Lavin KM, Overstreet BS, D'Acquisto LJ, et al. Cardiovascular and skeletal muscle health with lifelong exercise. J Appl Physiol (1985) 2018;125:1636-45.

25. Petajan JH, Gappmaier E, White AT, Spencer MK, Mino L, Hicks RW. Impact of aerobic training on fitness and quality of life in multiple sclerosis. Ann Neurol 1996;39:432-41.

26. Backus D, Moldavskiy M, Sweatman WM. Effects of functional electrical stimulation cycling on fatigue and quality of life in people with multiple sclerosis who are nonambulatory. Int J MS Care 2020;22:193-200.

27. Lambert CP, Archer RL, Evans WJ. Muscle strength and fatigue during isokinetic exercise in individuals with multiple sclerosis. Med Sci Sports Exerc 2001;33:1613-9.

28. Gehlsen GM, Grigsby SA, Winant DM. Effects of an aquatic fitness program on the muscular strength and endurance of patients with multiple sclerosis. Phys Ther 1984;64:653-7.
29. Shah A. Fatigue in multiple sclerosis. Phys Med Rehabil Clin N Am 2009;20:363-72.

30. Fernández-Muñoz JJ, Morón-Verdasco A, Cigarán-Méndez M, MuñozHellín E, Pérez-de-Heredia-Torres M, Fernández-de-las-Peñas C. Disability, quality of life, personality, cognitive and psychological variables associated with fatigue in patients with multiple sclerosis. Acta Neurol Scand 2015;132:118-24.

31. Razazian N, Kazeminia M, Moayedi H, Daneshkhah A, Shohaimi S, Mohammadi $\mathrm{M}$, et al. The impact of physical exercise on the fatigue symptoms in patients with multiple sclerosis: a systematic review and meta-analysis. BMC Neurol 2020;20:93.

32. Syndulko K, Jafari M, Woldanski A, Baumhefner RW, Tourtellotte WW. Effects of temperature in multiple sclerosis: a review of the literature. Neurorehabil Neural Repair 1996;10:23-34.

33. Jørgensen M, Dalgas U, Wens I, Hvid LG. Muscle strength and power in persons with multiple sclerosis - A systematic review and meta-analysis. J Neurol Sci 2017;376:225-41.

34. Petajan JH, White AT. Recommendations for physical activity in patients with multiple sclerosis. Sports Med 1999;27:179-91.

35. Motl RW, Sandroff BM, Kwakkel G, Dalgas U, Feinstein A, Heesen C, et al. Exercise in patients with multiple sclerosis. Lancet Neurol 2017;16:84856.

36. Motl RW, Pilutti LA. The benefits of exercise training in multiple sclerosis. Nat Rev Neurol 2012;8:487-97.

37. Andreasen AK, Stenager E, Dalgas U. The effect of exercise therapy on fatigue in multiple sclerosis. Mult Scler 2011;17:1041-54. 